\title{
Intellectualization of logistic supply chains on the basis of forecasting volumes of cargo transportation
}

\author{
Vitalii Gurnak, Lyudmila Volynets, ${ }^{*}$ and Ilona Khalatska \\ NTU, Department of Transport Law and Logistics, 010101, Kyiv, 1, M. Omelianovycha-Pavlenka Str., Ukraine
}

\begin{abstract}
Research shows that the accelerated economic movement towards a more intelligent model of development and rapid dissemination of knowledge contributes to the emergence of new modern logistics technologies and approaches to managing global supply chains. The dominant feature of the sustainable development of transport services is the invariant concept of management, the basis of which is the socioecological and economic model. Indicators of the transport sector show a decline in volumes of transportation, but the positive dynamics of growth is demonstrated by the agrarian sector, which produces half of all export volumes and provides one third of the currency revenues of the state.Factors that inhibit the effective functioning of the logistics chain are revealed. In particular, the technological orientation of railways, mainly on route transportation, highlighted the problem of uneven development of ports at ports and railway ports, as well as inconsistencies in grain volumes in Stevedoring companies' deals with real port facilities. In fact, there is a schedule of seasonal fluctuations in the transportation of cereals, in particular, their absence for 3-4 months per year.The rational model of management and intellectualization of grain supply logistic chain, which takes into account the indicators of artificial neural network forecasting and seasonal grain transportation parameter, is proposed.
\end{abstract}

\section{Introduction.}

The typical features of the current state of the transport industry activity are as follows. The volumes of transportation are rapidly falling, the critical level reached the financial condition of the entire industry.

Long-term drop in rail freight transport objectively depends on changes in gross national product (GDP). The analysis showed that the decisive impact on the volumes of freight traffic is precisely the dynamics of GDP, that is, in fact, industrial production. If this indicator grows, rail transport is almost proportionally increasing, and vice versa.

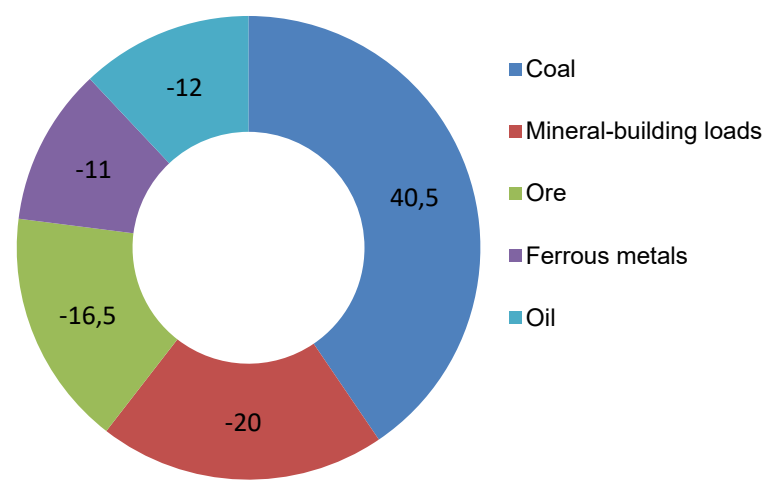

Fig.1. Falling volumes of rail transportation from 2013 to 2018, million tons
The main reasons are the temporary loss of the coalmining capacities of the Donbas and the annexation of the Crimea; a significant drop in export volumes due to the loss of production capacities for the production of ferrous metals (from $\$ 17.6$ to $\$ 11.6$ billion); reduction of volumes of production and export of domestic machine-building products (from $\$ 3.5$ to $\$ 0.7 \mathrm{bln}$ ); a significant drop in exports due to restrictions set by the Customs Union (43\%); reorientation by the Customs Union of transit of oil and petroleum products from Ukrainian ports to others; the decline in domestic production and consumption of mineral-building cargoes (imports decreased from $\$ 21.2$ to $\$ 13.4$ billion).

Against this background, the dynamical development and growth of production volumes, especially of the grain and oilseed group, is demonstrated by the agrarian sector of the state.

If 28 years ago Ukraine exported grain to North Africa and Europe, today, $40 \%$ of exports go to Asian countries, where the population growth is steady and quite high. According to $\mathrm{UN}$ forecasts, in 2050, the world will have 9.7 billion inhabitants, with the largest population growth expected in India. That is, an increase in the volume of agricultural production in general will have a guaranteed market of sales. Therefore, problems of logistic nature are at the forefront.

Modern trends in the development of the world economy in the context of global civilization dynamics and the formation of an information society show the intellectualization of all aspects of society's vital activity. The vast majority of developed countries actively

* Corresponding author: volinec 3@ukr.net 
develop a knowledge-based economic system that fundamentally changes the traditional approaches and models of logistics supply chain development. Logistics is not only a key function of the modern enterprise and business in general, but also, according to the figurative expression of German specialists, the "motor of the economy", that is, it affects the efficiency and competitiveness of the national economic system [1].

At the same time, it is important to note that the current stages of development of human society and strengthening its impact on the environment as a consequence of scientific and technological progress, increases the practical value of the environmental economy.

Problems of environmental substantiation of logistics chain intellectualization projects and management of investment processes taking into account the requirements of environmental protection are quite urgent. For today it is a priority because of the increasing importance of further implementation of sustainable development in the country's economic life. As you know, the concept of sustainable development includes three components: economic, social and environmental, which are inextricably linked. Therefore, the intellectualization of supply chain logistics should be based on the environmental concept of management based on the interconnection between ecosystems, social communities and economic systems, as well as conditions that ensure the steady state and progressive development of all three systems.

It should be noted that every year Ukrzaliznytsia transports grain more and more, but this dynamics lags behind the rate of productivity growth in the country. If the state carrier previously transported $80 \%$ of the grain collected in the country, three years ago - 68\%, then today - $63 \%$. At the same time, Ukraine has a unique, well-developed regionally-developed railway infrastructure. It makes it possible to reduce the cost of grain logistics. However, at the moment, we have a lot of low-impact stations and sections that have inherited from the socialist system of planned economy.

Based on the fact that the formation of a network of railways in different regions of Ukraine was conducted under the influence of specific factors. This necessitates the analysis of the current state of low-impact sections (DMDs) of railways and the decision of expediency of their further functioning, taking into account the peculiarities of economic development of certain geographical regions.

The results of the analysis of the current state of the MDS in the transport market show that on a significant number of them (up to $15.21 \%$ of the length of the network), the number of freight trains does not exceed 12 per day (Table 1).

Table 1. The number of low-impact sections in the railway transport

\begin{tabular}{|c|c|c|c|c|c|c|c|c|c|c|c|c|c|}
\hline \multirow{2}{*}{ Name of regional offices } & \multicolumn{2}{|c|}{$\mathrm{DN}-1$} & \multicolumn{2}{|c|}{$\mathrm{DN}-2$} & \multicolumn{2}{|c|}{$\mathrm{DN}-3$} & \multicolumn{2}{|c|}{$\mathrm{DN}-4$} & \multicolumn{2}{|c|}{$\mathrm{DN}-5$} & \multicolumn{2}{|c|}{ All } & \multirow{2}{*}{ 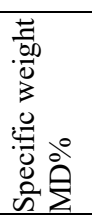 } \\
\hline & $\equiv$ & $\hat{\Sigma}$ & $\equiv$ & $\hat{\Sigma}$ & $\equiv$ & 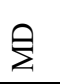 & 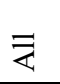 & $\Sigma$ & $\bar{\psi}$ & $\stackrel{\rho}{\Sigma}$ & $\equiv$ & $\hat{\Sigma}$ & \\
\hline Prydniprovska & 20 & 1 & 18 & 1 & 15 & 2 & 13 & 0 & 0 & 0 & 66 & 4 & 6,06 \\
\hline Southern & 5 & 2 & 22 & 1 & 5 & 1 & 16 & 0 & 7 & 0 & 55 & 4 & 7,27 \\
\hline South - West & 19 & 3 & 23 & 8 & 24 & 3 & 14 & 2 & 19 & 9 & 99 & 25 & 25,25 \\
\hline Odesa & 44 & 2 & 19 & 11 & 19 & 0 & 14 & 2 & 0 & 0 & 96 & 15 & 15,63 \\
\hline Lviv & 32 & 6 & 15 & 1 & 22 & 5 & 31 & 6 & 18 & 0 & 118 & 18 & 15,25 \\
\hline PJSC "Ukrzaliznytsya" & 120 & 14 & 97 & 22 & 85 & 11 & 88 & 10 & 44 & 9 & 434 & 66 & 15,21 \\
\hline
\end{tabular}

* - the Donetsk railway was not taken into account in connection with the military events in the East of Ukraine and transportation in the territory of the annexed ARC.

$\mathrm{DN}$ is the directorate at each regional branch.

Special attention is paid to the work of low-impact sections and stations, which are $46 \%$ and $30 \%$ on the network of national carriers respectively. According to the criteria for defining few activities, those who carry out less than $10 \%$ of work are considered such as on average on the network of Ukrzaliznytsya. The negative result of getting such an almost unused infrastructure exceeds UAH 7 billion a year [2].

At the same time, the European transport directives, which Ukraine has in accordance with the Association Agreement with the EU to implement its legislation, contains a norm according to which none of the companies in this sector of the market should work at a loss. Such a norm is enshrined in the latest edition of the draft Law of Ukraine "On Rail Transport". It also applies to JSC "Ukrzaliznytsya", which, in accordance with European regulations, should be the operator of public utilities infrastructure, which remains in state ownership.

In order to assess the effectiveness of the railway infrastructure, a whole package of data on cargo operations at stations, operational cargo turnover, cargo tension in the polling stations and a number of financial indicators were analyzed. As a result, groups of the most disadvantaged sections of the infrastructure were identified. According to the findings of the analysis on operational and economic efficiency of Ukrzaliznytsia's work with static geo-information visualization, today almost half of the railway facilities generate billions of 
losses to the state carrier. Specifically: $45.7 \%$ of all contracting companies together perform only $2.1 \%$ tonkilometrovoy work. For the maintenance of these inefficient sections and their functioning, the company directed more than UAH 7.8 billion, and received a total of UAH 543 million. of income, that is, less than $1 \%$ of all revenues from freight transportation.

Moreover, inefficient districts are located throughout Ukraine. At the same time, in comparison with 2016 their number increased. In 2018, the worst financial result was obtained at Yahodyn-Kovel $(66 \mathrm{~km})$, KovelSarny $(142 \mathrm{~km})$ and Uzhgorod-Syanki $(90 \mathrm{~km})$ (Lviv railway); T. Shevchenko - Pomichna (129 km), Tsvetkovy - Khrystynivka (148 km), Khrystynivka Timanovka $(113 \mathrm{~km})$ and Kherson-Vadim (103 km) (Odesa railway); Surske - Apostolove (139 km) (Prydniprovska railroad), Ziatkivtsi - Vinnitsa (62 km) (Southwest railway) and Lyubotin - Smorodinov (112 $\mathrm{km})$ (Southern railway).

The results of diagnostics of low-impact sections allowed to reveal a considerable reserve of carrier and throughput capacity. It is established that there is a significant under-utilization of production capacities. The main reason - in low-impact areas there is a need for special, simplified operation methods, implementation of which can significantly reduce the cost of transportation, the level of tariff, which, in turn, will allow attracting more consumers of rail transport products and approach the solution to the problem of loss-making low-impact areas and the possibility of realizing a forecast of their activities in the future.

In the prevailing volatile and difficult economic, political and social conditions, railways continue to be permanently working and attractive to most cargo owners by mode of transport [3].

The problem of developing the system of forecasting freight volumes in modern conditions has become particularly relevant, since analyzing and forecasting volumes of cargo transportation is an important tool for developing effective management decisions and will involve the creation of intelligent logistics supply chains and the planning of the need for material, labor and financial resources.

\section{Analysis of literary data and problem statement}

The volumes of grain production in Ukraine far exceed the needs of the domestic market. At present, most domestic grain is exported. At the same time, state strategic goals have been determined and continue to increase grain production to 80 million tons. However, the grain market infrastructure does not fully meet the needs of growing traders.

In particular, in the operation of the transport and logistics system, difficulties are observed with the delivery of export batches to ports, which affects the efficiency of the utilization of terminal capacities. First of all, this is due to the increasing load on the transport infrastructure. Thus, it became problematic for railway transport to submit wagons in all applications.
Today, rail transport occupy a dominant share (about $60 \%$ ) in the total volumes of cereals transportation. Distribution and use of UZ rail cars takes place in a nontransparent manner.

Obviously, the rules and tariffs for using the railway infrastructure should be equally transparent for all participants in the logistics chain.

The logistics chain and its parts are the subject of research by many foreign and domestic scientists. Logistics aspect of supply chain management is devoted to work [3]. The paper [2] describes the need to change the priorities of investment in the development of transport infrastructure in modern conditions and increase the efficiency of the logistics supply chain. The main areas of logistics in the agricultural sector are reserves and transport. The decision of issues of optimization of export cargo flows and development of infrastructure of different types of transport for their effective interaction is considered in the paper $[2,4]$.

Theoretical and methodological bases of research were the scientific works of scientists in the field of planning and forecasting of various spheres of activity. In $[1,5]$ the necessity of forecasting of the future volumes of transportation by railroad during the formation of the level of tariff for transportation of goods is indicated. Empirical results [6] confirm that the artificial neural network is an effective tool for forecasting the exchange rate. This technique provides evidence that there is an opportunity to extract hidden information for reliable forecasting of the future.

The decision-making process when planning the required number of rolling stock is considered one of the most problematic issues for the transport industry. The paper [7] reveals a new approach to determining the size of the fleet in air travel with the help of Monte Carlo modeling is being developed. Applying this method, the airline receives maximum profit. Such a decision procedure can also be applied on rail transport to detect the required number of carriages for forecasting cargo transportation.

Forecasting flows is an important component of transport systems. The adoption of unwarranted decisions in the transport of goods leads to a rise in monetary expenditures in the railway industry. Transportation management should provide the choice and implementation of only optimal solutions that can comprehensively assess the performance of vehicles for different transportation options [8].

In order to accurately predict the volumes of freight transportation by railways of Ukraine and the possibility of extracting hidden information during the planning of passenger traffic, the above-mentioned current experience of forecasting was taken into account both in transport and in other sectors.

\section{The purpose and tasks of the study}

The aim of the work is to improve the management of logistic supply chains on the basis of forecast values of volumes of cargo transportation.

To achieve this goal, the following tasks were set: 
- to analyze the work of the transport industry and the volume of transportation of grain;

- To develop a model of forecasting of volumes of cargo transportation and to intellectualize the logistic chain of supply of grain;

- to propose a mathematical model, increase the efficiency and intellectualization of the logistic supply chain.

\section{Investigation of the forecasting method for determining the volume of cargo transportation}

The task of forecasting was realized due to the structural model on the basis of artificial neural network (ANN). This method of forecasting has high properties of adaptation to input data variables through self-study. The main advantage of neural network models is nonlinearity, that is, the ability to establish nonlinear relationships between future and actual values of processes. Other important advantages include: adaptability, mass-compliance (parallel structure of ANN accelerates computation) and uniformity of analysis and design. In this case, the disadvantages of ANN are the lack of transparency in modeling, the complexity of choosing architecture, high requirements for the consistency of the training sample, the complexity of the choice of learning algorithm and the resource-intensiveness of the learning process [9].

Equation of the mathematical structure of the neuron:

$$
\begin{gathered}
\mathrm{y}=f(u), \\
U=\sum_{i=1}^{n} w_{i} x_{i}+w_{0}
\end{gathered}
$$

where $w_{i}, x_{i}$ - respectively, the forces at the inputs in the neurons and the magnitudes of synaptic bonds;

$w_{0}$ - displacement coefficient of the neuron (weight of the additional input);

$U$ - induced logical field;

$f(u)$ - transfer function or activation function.

The additional input and its corresponding weight are used to initialize the neuron. Under initialization, the shift in the activation function of the neuron along the horizontal axis, that is, the formation of the threshold of sensitivity of the neuron, is meant.

The method of communication of neurons defines the architecture of the neural network. According to the work [10], depending on the way neurons communicate, the networks are divided into:

- direct distribution networks;

- recurrent neural networks;

- radial basis functions;

- Self-organizing maps or Kohonen Networks

Probably, the architecture of multilayer neural networks is now used most often. The network is composed of many sensor elements (input nodes) that form the input layer of one or more hidden layers of computing neurons and one source layer of the neurons.

The multilayer neural network can simulate the function of practically any degree of complexity, and the number of layers and the number of elements in each layer determine the complexity of the function. Determining the number of intermediate layers and the number of elements in them is an important issue when constructing.

Neural networks are especially effective for systems that are characterized by a high degree of nonlinearity. In order to evaluate the ability of the neural network to effectively predict the volumes of freight transportation by rail, first of all, it is necessary to analyze the preliminary statistics of freight traffic.

Forecasting is realized with the help of the fully connected multilayer perceptron (MLP, Multilayer perceptron) with direct distribution, architecture 12-96-1. The signals propagate in one direction, starting from the input layer of the neurons, through the hidden layers to the output layer and on the output neurons the result of the processing of the signal is obtained.

The activation function of the input layer is identical, that is the input signals are not converted, but transmitted to the next layer. In this network, unlike its predecessor, perceptron Rosenblatt, uses nonlinear activation functions, namely sigmoid. It allows you to amplify weak signals and not overload with powerful signals. Such a nonlinear actuation function solves the dilemma of noise saturation. On the coiled layer, the logistic function (3) is used, and at the output - the hyperbolic tangent (4)

$$
\begin{gathered}
f(U)=\frac{1}{1+e^{-u}}, \\
f(U)=\frac{e^{u}-e^{-u}}{e^{u}+e^{-u}}
\end{gathered}
$$

At the output of the neuron we obtain the forecast value of the volumes of cargo transportation by rail

\subsection{Results of modeling and intellectualization of the grain supply logistics chain}

As input data, statistical observations on volumes of transportation of grains and products of reminiscing from 2004 to 2018 were used. For the training sample $90 \%$ of the values were allocated, and for the control $10 \%$. As a test sample for cross-check, real volumes of grain shipments for the 8 months of 2018 were used. The results of forecasting are shown in Fig. 2.

The adequacy of the model can be judged by the diagram of the distribution of residues (Fig. 3), in the ideal case the graph resembles the normal distribution law and has a bell-shaped shape.

The relationship between incoming and outgoing data is presented in Fig. 4.

Judging by the figure, we can conclude that the meurezh catches the general tendency of a number. 


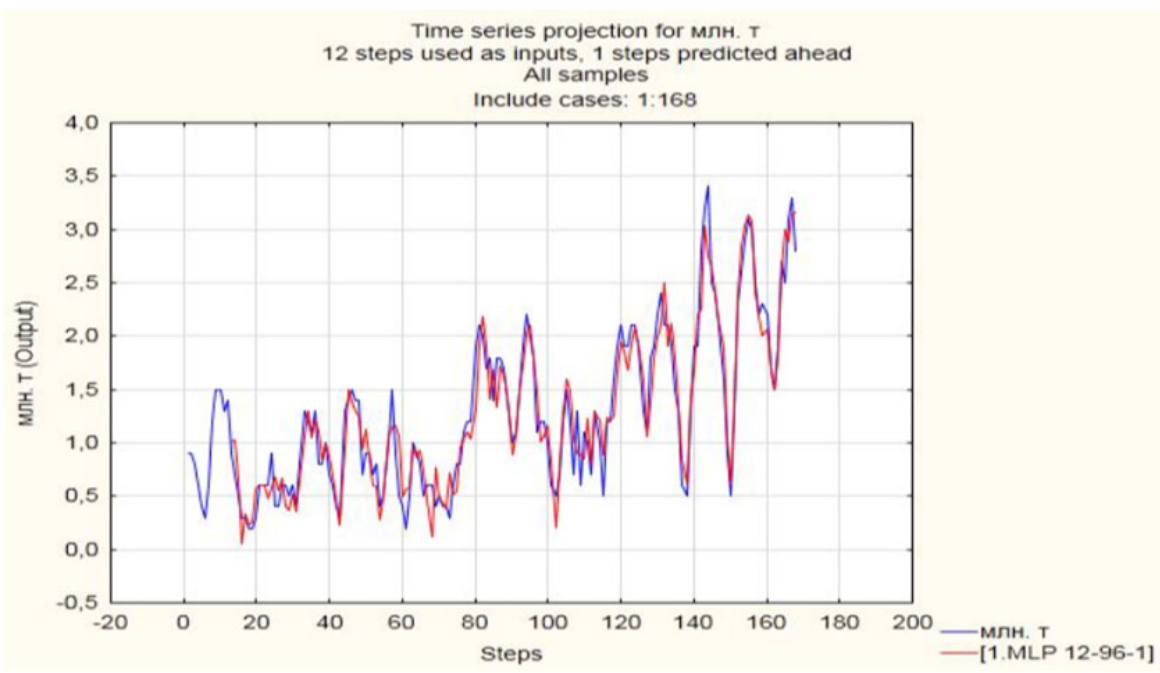

Fig. 2. Comparison of the predictive series with real values

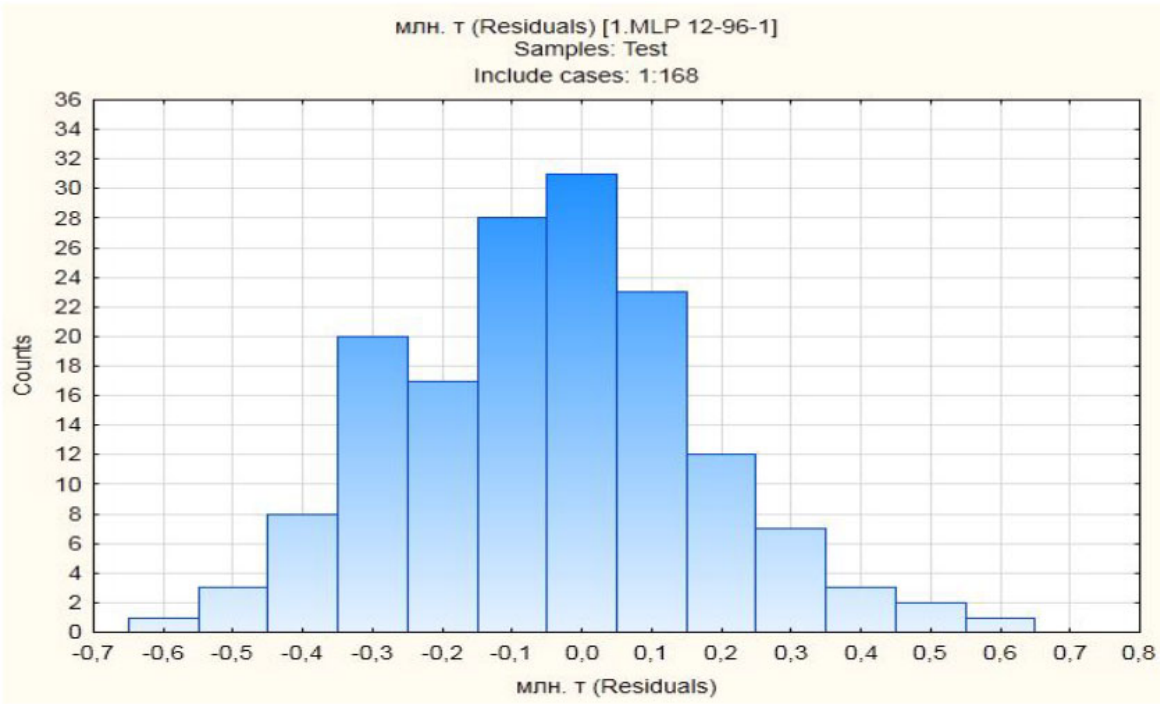

Fig. 3. Chart of residue distribution

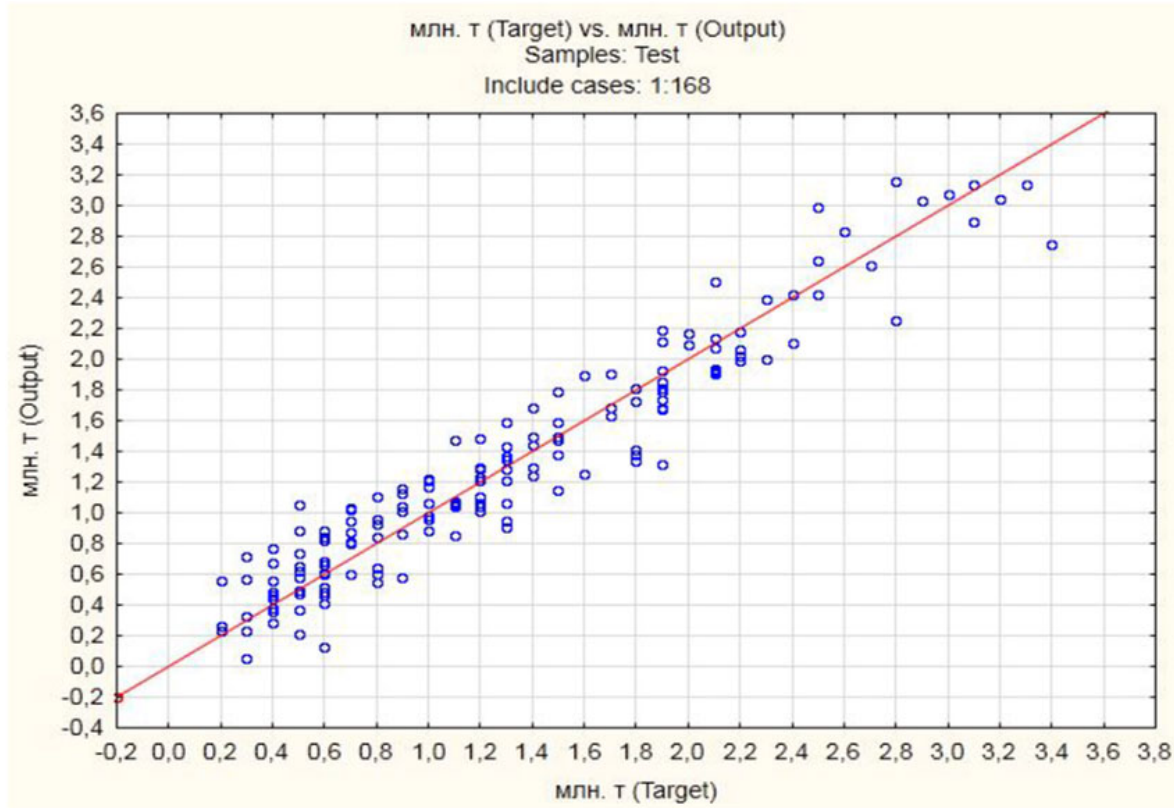

Fig. 4. Schedule of the relationship between incoming and outgoing signals 
The results of the cross-check are shown in Fig. 5

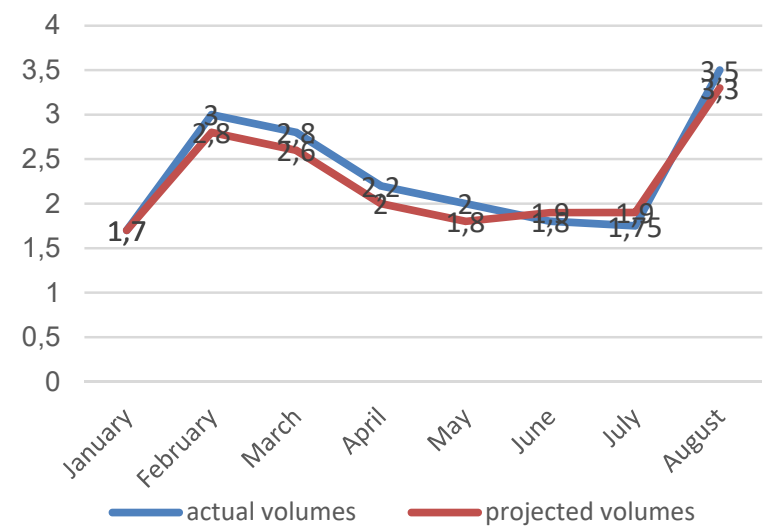

Fig. 5. Comparative schedule of forecast and actual volumes of transportation of grain and reminiscent products in 8 months 2018

The value of the accuracy of the forecasting of traffic is determined by the value of the average absolute percentage error (SAPS). The magnitude of the accuracy of pro-rigging is the concept of the exact opposite error of prediction. If the prediction error is high, then the accuracy is small, and vice versa, if the prediction error is small, then the accuracy is high.

Comparison of actual and forecast data of the investigated cargo transportation period is presented in Fig. 6

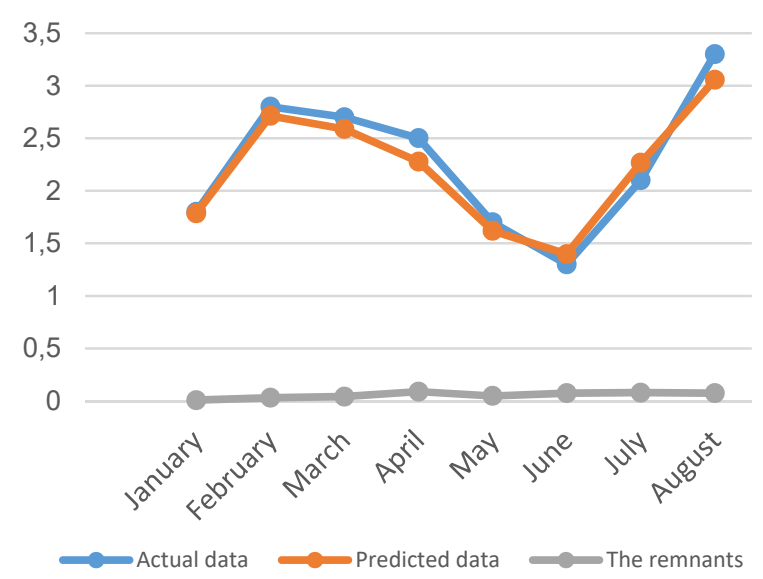

Fig. 6. Comparison of actual and forecast data on the volumes of transportation of grain and reminiscent products

Speaking of high accuracy, we always talk about a low forecast error. The forecast error is to a degree characterized by the accuracy of the applied forecasting technique. The experiment showed that the average absolute error rate of grains and maize products transmitted during the first eight months of 2018 amounted to $5.7 \%$. Given that rail transport is a fairly inert system, the AMD indicator of $5.7 \%$ is sufficient to make managerial decisions.

Transport industry is quite inert system. It is difficult to make operational management decisions. Therefore, it is necessary to provide high-quality forecasting for taking tactical administrative decisions for some time before the event's time for effective work of the industry.

Knowing the predicted level of cargo transportation, it is possible to determine the required number of cars of the type of container that will meet the conditions for the transfer of this cargo, that is, to improve the logistics chain of grain supply. Forecast values of carriage rates for grain and reminiscent products are shown in Fig. 7

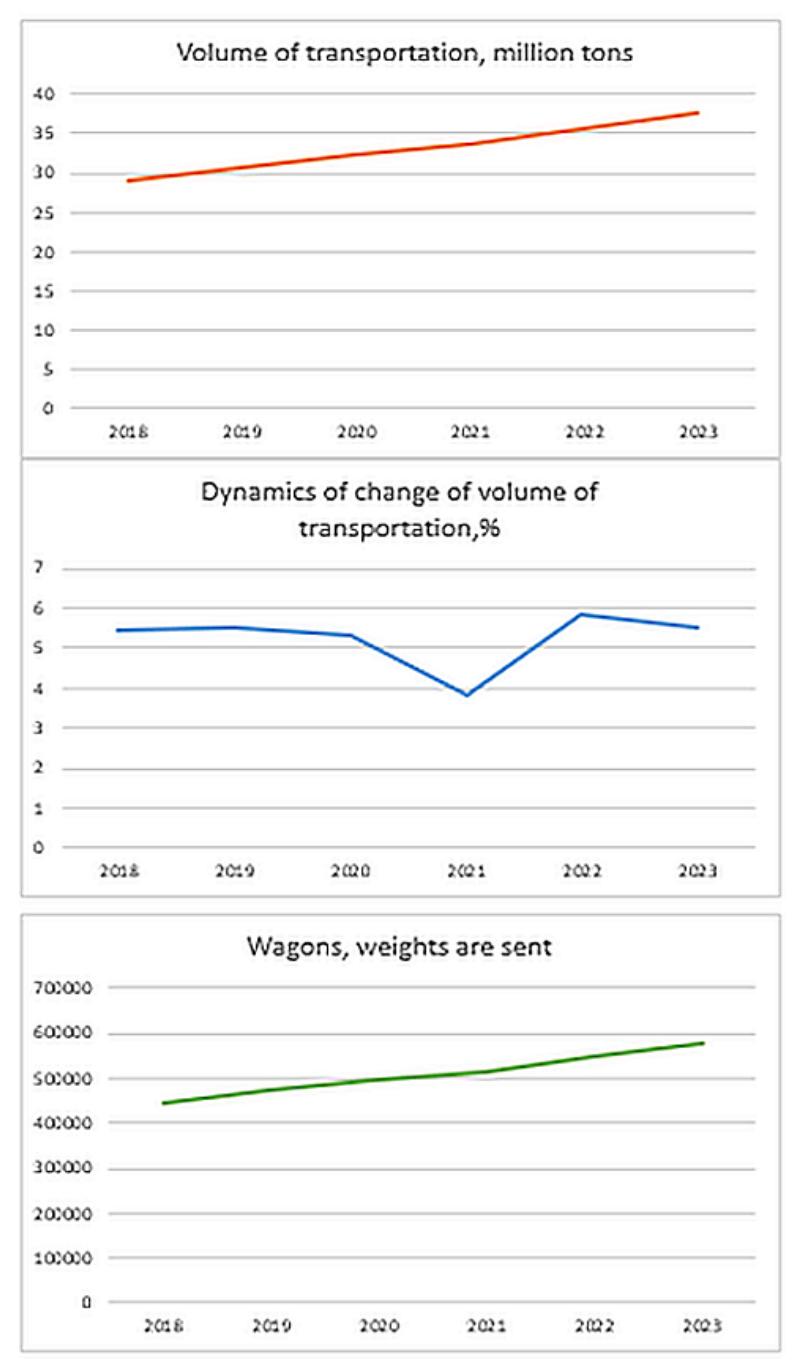

Fig. 7. Projected values of carriage rates for grain and maize products

Due to forecasting of volumes of transportation for the next period it is possible to improve the efficiency of management of supply chains and realize the agrarian potential, especially in peak periods. The foregoing values of freight transportation rates were highlighted in subsequent calculations.

\subsection{Formalization of management of supply chains of grain}

The presence of integrated systems of flow processes in logistics chains is considered an important condition for an industrial enterprise. Ensuring continuity and reducing aggregate costs in all branches of the logistics chain from manufacturer to consumer should be based 
on the rational use of rolling stock to carry out the planned volumes of transportation.

The drafting of the distribution plan for wagons depends mainly on the number of wagons that are not needed for carriage. Also, an important planning parameter is the location of wagons in a specific time period.

Under the optimal organization of logistic supply chains is minimization of operating costs for the carriage of goods. In calculating the plan for the formation and operational plan of vehicle management, the main criterion for choosing promotion is the minimum operating cost. But the same approach to calculating the transportation plan for different types of cargo is not optimal. Therefore, in order to find the optimal variant of the movement of material flow, it is suggested to take into account the parameter of uneven transport or seasonality. The above studies have shown that for different cargoes the coefficient of unevenness of transportation is uneven. The choice of a rational plan for the distribution of wagons on the railway network is presented in the form of a target function:

$$
\begin{array}{r}
C\left(x_{i j}\right)=\sum_{i=1} \sum_{j=0} x_{i j} \times k_{\mathrm{H}} \times \delta_{\text {зав }} \times d_{i j}^{\text {зав }}+ \\
+\sum_{i} \sum_{j} x_{i j} \times k_{\mathrm{H}} \times \delta_{\text {пор }} \times d_{i j}^{\text {пор }}+\Delta D / \Delta x_{i j} \rightarrow \text { min }
\end{array}
$$

where $C$ - expenses for transportation of cargo, UAH; $x_{i j}$ - variable number of cars moving from station $i$ to station $j$;

$\mathrm{k}_{\mathrm{H}}$ - coefficient of uneven cargo transportation;

$\delta_{\text {зав }}, \delta_{\text {nор }}$ - the proportion of loaded wagons and wagons correspondingly going from station $i$ and stations $j$;

$d_{i j}^{\text {зав }}, d_{i j}^{\text {пор }}$ - expenses related to the transfer of loaded and empty wagons respectively;

$\Delta \mathrm{D}$ - specific costs due to an increase in carload above average, UAH;

$\Delta \mathrm{x}_{\mathrm{ij}}-\mathrm{a}$ specific increase in the number of cars transported from stations $i$ to the station $j$.

The following factors are taken into account as limitations:

- Limitations related to bandwidth of stations and stations:

$$
\sum_{\mathrm{i}=1} N_{\text {наяв }}^{\mathrm{cт} / \text { дільн }}-\sum_{j=0} N_{\text {потр }}^{\mathrm{cт/дільн}} \geq \Pi ;
$$

- Limitation on the length of the the freight train:

$$
\sum_{e=1}^{S} \mu_{e}(e) \leq L_{e}
$$

- Limit taking into account the time of delivery of the goods:

$$
t_{\text {нав }}+t_{\text {форм }}+t_{\text {ш.прям }} \leq \mathrm{T}
$$

Provided that the required number of wagons is delivered to load points:

$$
1 \leq x_{i j} \leq \frac{a_{i}}{q_{\mathrm{cT}}}
$$

where $\sum N_{\text {наяв }}^{\text {ст/дьн }}-$ available bandwidth of stations and sections respectively in trains; $\sum N_{\text {потр }}^{\text {ст/дільн }}-$ need a bandwidth of stations and stations corresponding to what is necessary for carrying out a plan of transportation in trains;

$\Pi$ - the number of trains that can be involved in the distribution of wagons in directions for railways;

$\mu_{e}(e)$ - the intensity of the carriage at the e-th ironwork station;

$\mathrm{S}$ - the number of stations that the train enters;

$L_{e}$ - the length of the receiving and sending tracks at the e-station;

$t_{\text {нав }}-$ load time xij of cars, h;

$t_{\text {форм }}$ - duration of train formation, $\mathrm{h}$;

$t_{\text {ш.прям }}-$ time of finding a train on the route, hour;

$\mathrm{T}$ - time of delivery of cargo, hour;

$a_{i}$ - quantity of cargo in i-th load point, t;

$q_{\mathrm{cT}}-$ average static load of the car, $\mathrm{t} /$ weights.

Application of the result of the decision of the proposed model gives the opportunity to make rational management decisions and intellectualize the logistics supply chain. That is to plan and promptly execute the distribution depending on the demand for freight wagons. This model takes into account both annual fluctuations of volumes of transportations, and monthly. And also the traffic of vehicles and railway infrastructure.

\section{Conclusions}

1. The analysis of the management of supply chains in the structure of logistics services of domestic enterprises of the agrarian sector. Indicators of the transport sector indicate a decline in transportation volumes, but the positive dynamics of growth is demonstrated by the agrarian sector, which produces half of all export volumes and provides one-third of the currency revenues of the state.

2. Formed a neural network model for predicting traffic volumes. This method of forecasting has high properties of adaptation to input data variables through self-study. The magnitude of the accuracy of the forecasting of traffic is determined by the value of the average absolute percentage error, which was $5.56 \%$. Given that the transport industry is a fairly inert system, such an indicator is sufficient for making managerial decisions.

3. In order to find rational management decisions and intellectualization of the grain supply logistic chain, it is suggested to take into account the parameter of nonuniformity of transportation or seasonality. For optimality we accept minimization of operating expenses for transportation of cargo.

On the basis of the received data on the volumes of transportation and using the optimization model, a solution was obtained for the optimal plan for distribution of wagons. The procedure for distributing wagons is quite universal and allows for a real-time adjustment of the train formation plan. The proposed model can be used to make rational management decisions while improving the efficiency and intellectualization of logistic supply chains. 


\section{References:}

1. V.M. Gurnak, L.M. Volynets, M.V. Gurnak, PMSAL, 9, 33-39 (2017)

2. V.M. Gurnak, L.M. Volynets, CSW SUIT, 41(1), 717 (2018)

3. T.A. Vorkut, O.E. Bilonog, A.M. Dmitrichenko, Yu.O. Tretijchenko, Supply Chain Management: Logistic Aspect (NTU, 2017)

4. L.M. Volynets, V.M. Gurnak, The Eighth ISPC, 247-250 (2018)

5. S. M. Proshchuk, G. E. Bogomazova, R. A. Puri, CSW UkrSURT, 164, 161-169 (2016).
6. R. P. Pradhan, R. Kumar, JMR, 4, 111-117 (2010)

7. Y. Wang, H. Sun, J. Zhu, B. Zhu, MPE, 2015, 1-13 (2015)

8. S. Panchenko, O. Lavrukhin, O. Shapatina, EEJET, 3 (85), 39-45 (2017)

9. V. V. Kruglov, V. V. Borisov, Artificial neural networks. Theory and practice (Hotline - Telecom, 2002)

10. S. Khaikin, Neural networks (LLC I. D. Williams, 2006) 